\title{
Obituary to an Eminent Member of AMI, Dr Dadarwal
}

\author{
S. S. Dudeja ${ }^{1}$ Pratyoosh Shukla ${ }^{2}$ Vipin Chandra Kalia ${ }^{3}$
}

(C) Association of Microbiologists of India 2019

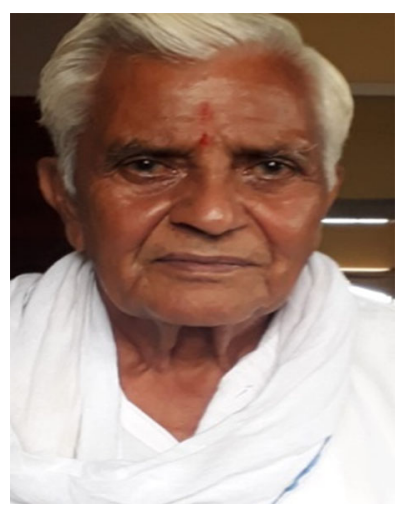

Prof. Kalu Ram Dadarwal (2.10.1944-28.7.2018)

Dr Kalu Ram Dadarwal was born on 2nd October 1944 at village Sanga ka bass in district Jaipur, Rajasthan. After completing BSc (Ag) from the University of Udaipur, he completed his MSc \& PhD from IARI, New Delhi. In 1972, he joined the department of Microbiology, IARI as an as

Vipin Chandra Kalia

vckaliaku@gmail.com

S. S. Dudeja

ssdudeja@gmail.com

Pratyoosh Shukla

pratyoosh.shukla@gmail.com

1 Department of Bio \& Nanotechnology, Guru Jambeshwar University of Science \& Technology, Hisar 125001, India

2 Department of Microbiology, Maharshi Dayanand University, Rohtak, Haryana 124001, India

3 Department of Chemical Engineering, Konkuk University, Seoul 05029, Republic of Korea
Assistant Professor and in 1975, he was selected as a Microbiologist in the department of Microbiology, at HAU, Hisar. In 1982 he was selected as the ICAR National Fellow at HAU and later served as the Professor and Head of the department of Microbiology and the Dean of COBS\&H of HAU. He also served as a FAO/UNDP National consultant for Bio fertilizer production and quality control. He was recipient of scholarship and fellowship during his MSc and Ph.D at IARI. He was engaged in teaching UG and PG students at IARI and later at HAU. He guided 5 students for their Master's degree and 7 students for their Ph.D. He also served as a post graduate examiner at a number of universities and committees of ICAR.

His major field of research was Biological nitrogen fixation and he published 75 research papers in National \& International journals, apart from three books and review articles. He participated in many national conferences.

During his career at HAU, he took active part in the activities of the Association. In 1987 with Professor P. Tauro resurrected the ailing AMI and its journal by becoming the Treasurer of the Association 1987-1992. Together they made several key decisions and within a span of 4 years, restored the financial health of AMI. He then served AMI as its General Secretary (1992-95) followed by Editor in Chief of Indian Journal of Microbiology (1996-98) and finally as its president (AMI President 2001). No other member of the AMI has served this association with so many capacities as Dr. Dadarwal.

Dr Dadarwal was also a fellow of NAAS and a FAMI and was recipient Dr GB Manjrekar Memorial and Life Time achievement awards of AMI. The HRD ministry nominated Dr Dadarwal for a study tour of USA and he also visited Australia for a study of the BNF programme in Australia. He superannuated from the department of Microbiology CCS HAU on Oct 31, 2004 and moved to his 
farmhouse in Sanga ka bass in Jaipur Rajasthan. On 28.7.2018, he passed away after an accidental electrocution. He leaves behind two daughters and one son.
In Dr Dadawlwal's untimely demise, the Association of Microbiologist has lost a one of its most very member. 